\title{
Performance Comparison of Routing protocols for MANETs.
}

\author{
Anshu Bajaj, Tripti Malhotra \\ Department Of Electronics And Communication,Dviet,Karnal
}

\begin{abstract}
Mobile ad hoc network is an autonomous system, where nodes/stations are connected with each other through wireless links. There is no restriction on the nodes to join or leave the network, therefore the nodes join or leave freely. Mobile ad hoc network topology is dynamic that can change rapidly because the nodes move freely and can organize themselves randomly. This property of the nodes makes the mobile ad hoc networks unpredictable from the point of view of scalability and topology. This paper highlights routing protocols in MANETs (Mobile Ad Hoc Networks). In general, routing protocols for MANETs are designed based on the assumption that all participating nodes are fully cooperative. However, due to the open structure and scarcely available battery-based energy, node misbehaviors may exist. In this paper AODV and DSR routing protocols are to be discussed and measure the performance in the end to end delay, PDF, throughput with constant mobility. For the implementation purpose we have used network simulator-2 (NS-2)
\end{abstract}

Keywords: - Mobile Ad Hoc Networks (MANETs), routing misbehavior, Ad Hoc On Demand Routing Vector (AODV), Dynamic Source Routing (DSR).

\section{INTRODUCTION}

An ad hoc network is a collection of nodes that do not need to rely on a predefined infrastructure to keep the network connected. Ad hoc networks can be formed, merged together or partitioned into separate networks on the fly, without necessarily relying on a fixed infrastructure to manage the operation. Nodes of ad hoc networks are often mobile, which also implicates that they apply wireless communication to maintain the connectivity, in which case the networks are called as mobile ad hoc networks (MANET). Mobility is not, however, a requirement for nodes in ad hoc networks, in ad hoc networks there may exist static and wired nodes, which may make use of services offered by fixed infrastructure. Ad hoc networks may be very different from each other, depending on the area of application: For instance in a computer science classroom an ad hoc network could be formed between students' PDAs and the workstation of the teacher. The performance of nodes in ad hoc networks is critical, since the amount of available power for excessive calculation and radio transmission are constrained. In addition, the available bandwidth and radio frequencies may be heavily restricted and may vary rapidly. Finally, as the amount of available memory and CPU power is typically small, the implementation of strong protection for ad hoc networks is non-trivial. The main objective of this paper is study of different routing protocols like and AODV and DSR etc.

\section{Ad-Hoc routing Protocols}

Figure 1 depicts broad classification of different routing Protocols. The characteristics of each are described in the sub sections.

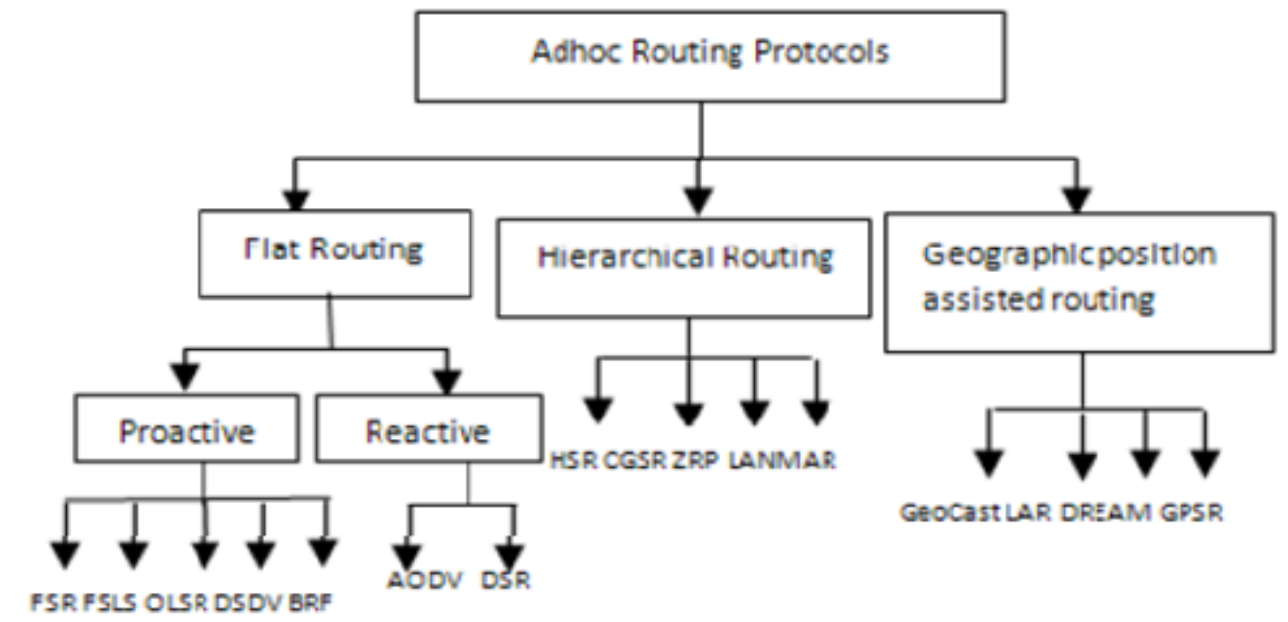

Figure 1: Routing Protocol 
The routing protocols DSR and AODV are often used as reference protocols when a new protocol shall be evaluated. To understand the characteristics of these protocols they are described in the sections below and their performance is evaluated in section 3 .

\subsection{DSR}

DSR is an entirely on-demand ad hoc network routing protocol composed of two parts: Route Discovery and Route Maintenance. In DSR, when a node has a packet to send to some destination and does not currently have a route to that destination in its Route Cache, the node initiates Route Discovery to find a route; this node is known as the initiator of the Route Discovery, and the destination of the packet is known as the Discovery's target. The initiator transmits a ROUTE REQUEST packet as a local broadcast, specifying the target and a unique identifier from the initiator. Each node receiving the ROUTE REQUEST, if it has recently seen this request identifier from the initiator, discards the REQUEST. Otherwise, it appends its own node address to a list in the REQUEST and rebroadcasts the REQUEST. When the ROUTE REQUEST reaches its target node, the target sends a ROUTE REPLY back to the initiator of the REQUEST, including a copy of the accumulated list of addresses from the REQUEST. When the REPLY reaches the initiator of the REQUEST, it caches the new route in its Route Cache.

Route Maintenance is the mechanism by which a node sending a packet along a specified route to some destination detects if that route has broken, for example because two nodes in it have moved too far apart. DSR is based on source routing: when sending a packet, the originator lists in the header of the packet the complete Sequence of nodes through which the packet is to be forwarded. Each node along the route forwards the packet to the next hop indicated in the packet's header, and attempts to confirm that the packet was received by that next node; a node may confirm this by means of a link-layer acknowledgment, passive acknowledgment, or network-layer acknowledgment. If, after a limited number of local retransmissions of the packet, a node in the route is unable to make this confirmation, it returns a ROUTE ERROR to the original source of the packet, identifying the link from itself to the next node as broken. The sender then removes this broken link from its Route Cache; for subsequent packets to this destination, the sender may use any other route to that destination in its Cache, or it may attempt a new Route Discovery for that target if necessary.

\subsection{AODV}

AODV is a reactive protocol that determines routes solely on-demand. It is based on the distance vector technology. The hosts only know the next hop to every destination. When a source host wants to send packets to the destination and cannot get the routes from its routing table, it will broadcast a Route Request (RREQ). The receivers may establish the routes back to the source host through the paths that they get the RREQ. If the receiver has an active route to the destination, it will be unicast a Route Reply (RREP) back to the source. Otherwise, the RREQ will be re-broadcast further. If a reply is sent, all hosts along that path may record the route to the destination through this packet. Because there may exist multiple exclusive paths between two hosts, a mobile host can receive the same RREQ more than once. To prevent the same request from being broadcast repeatedly, every request is uniquely identified by a Host ID, Broadcast ID couple. Every host keeps a record for the RREQs that have been processed. The mobile hosts send out the Route Error (RERR) packets to their neighbours to report broken paths and activate the route re-discovery procedure. To avoid routing loop and identify the freshness of the route, destination sequence number is introduced. The sequence number of a mobile host can only be updated by itself in monotonically increasing mode. A larger sequence number denotes a fresher route. The sequence number is carried in both RREQ and RREP. The sequence number in RREP must be larger than or equal to the one carried in corresponding RREQ to avoid the source host to adopt a stale path. When more than one path represented by different RREPs is available, the one with the largest destination sequence number is used. If several paths have the same sequence number, the shortest one is chosen. AODV's desirable features are its low byte overhead in relatively static networks and loop free routing using the destination sequence numbers.

\section{DESIGN AND IMPLEMENTATION}

We implemented our algorithm in NS-2 simulator. Cryptography algorithm (RSA) is implemented in C++ and we used its interface in TCL for data transfer. To perform the simulation, we used the following simulation objects and applications:

\subsection{Performance Analysis of AODV}




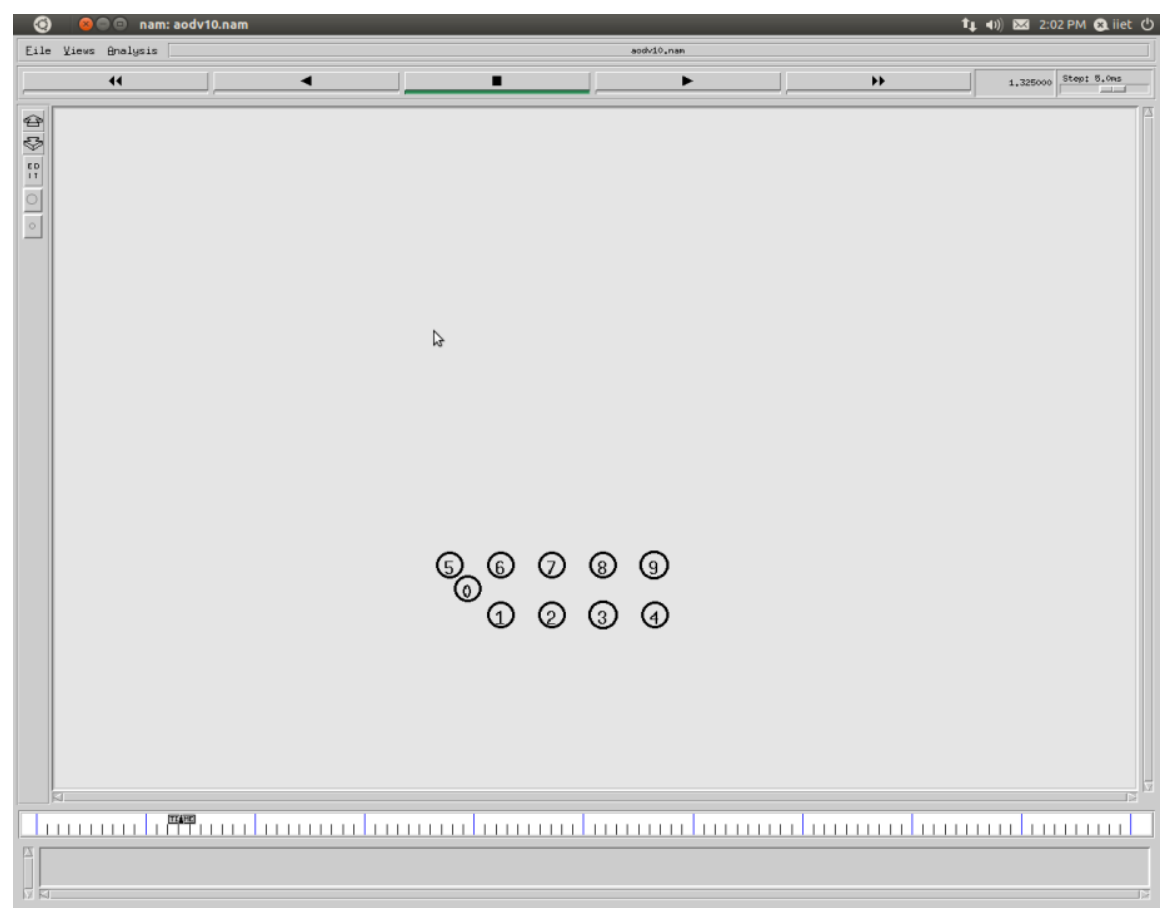

Figure: 3.1 Simulation with AODV Initial stage-I

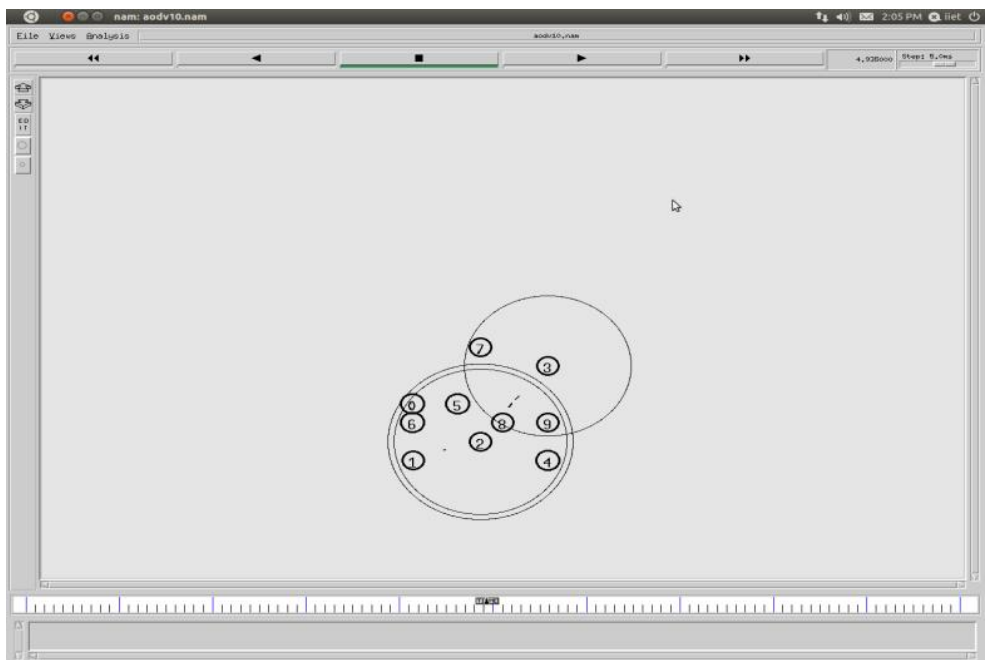

Figure: 3.2 Data transfer AODV

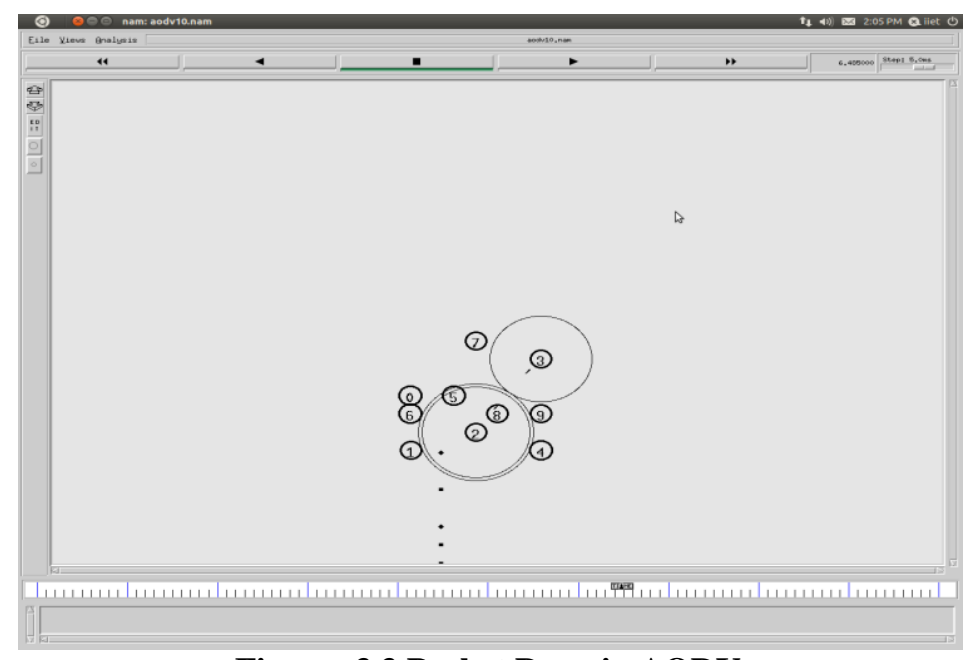

Figure: 3.3 Packet Drop in AODV 


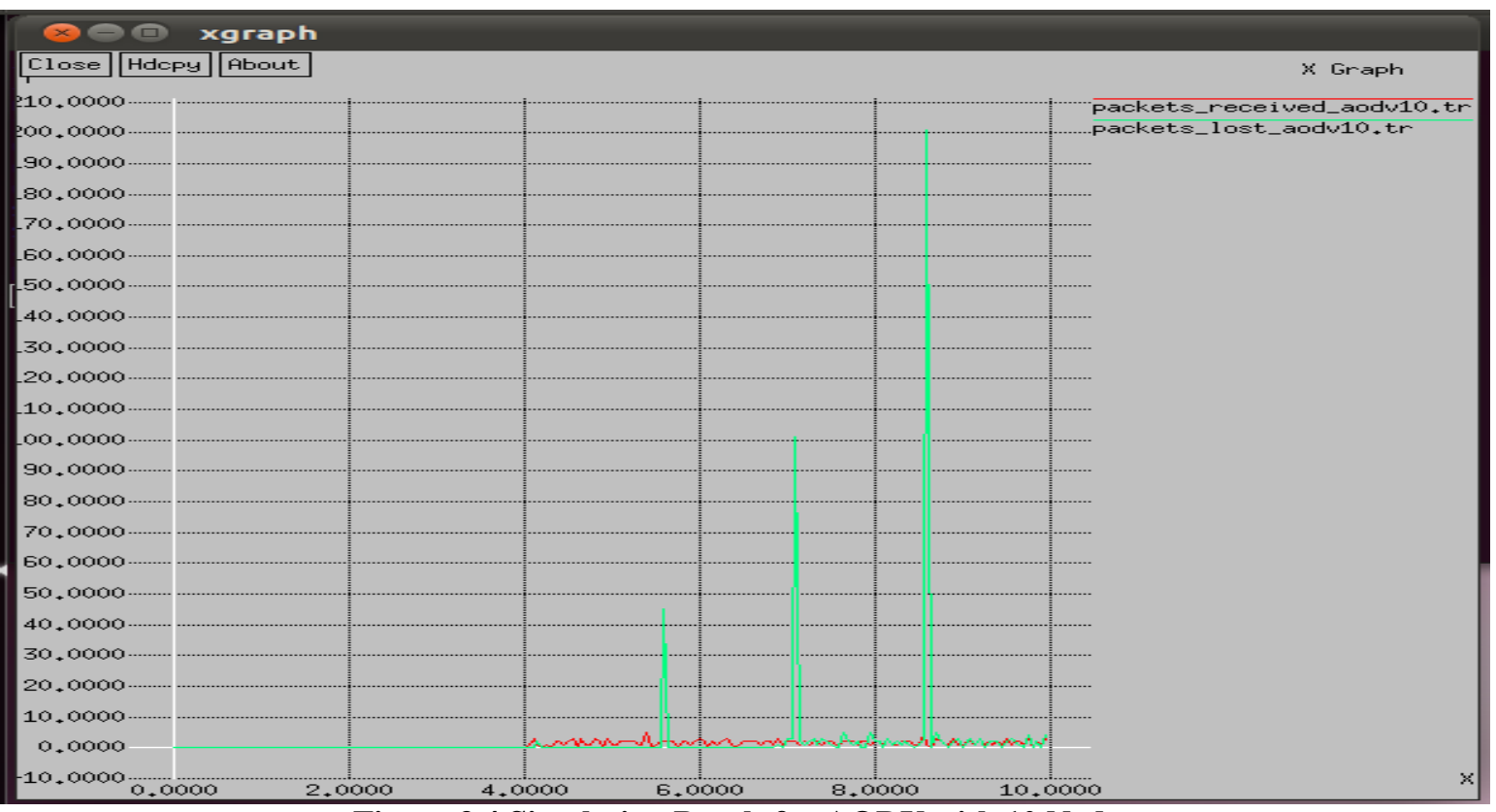

Figure 3.4 Simulation Result for AODV with 10 Nodes

\begin{tabular}{|l|l|}
\hline Protocols & AODV \\
\hline End-to-End Delay(ms) & 369.072 \\
\hline Throughput(kbps) & 405.39 \\
\hline
\end{tabular}

Table 3.1 Simulation Result for AODV with 10 Nodes

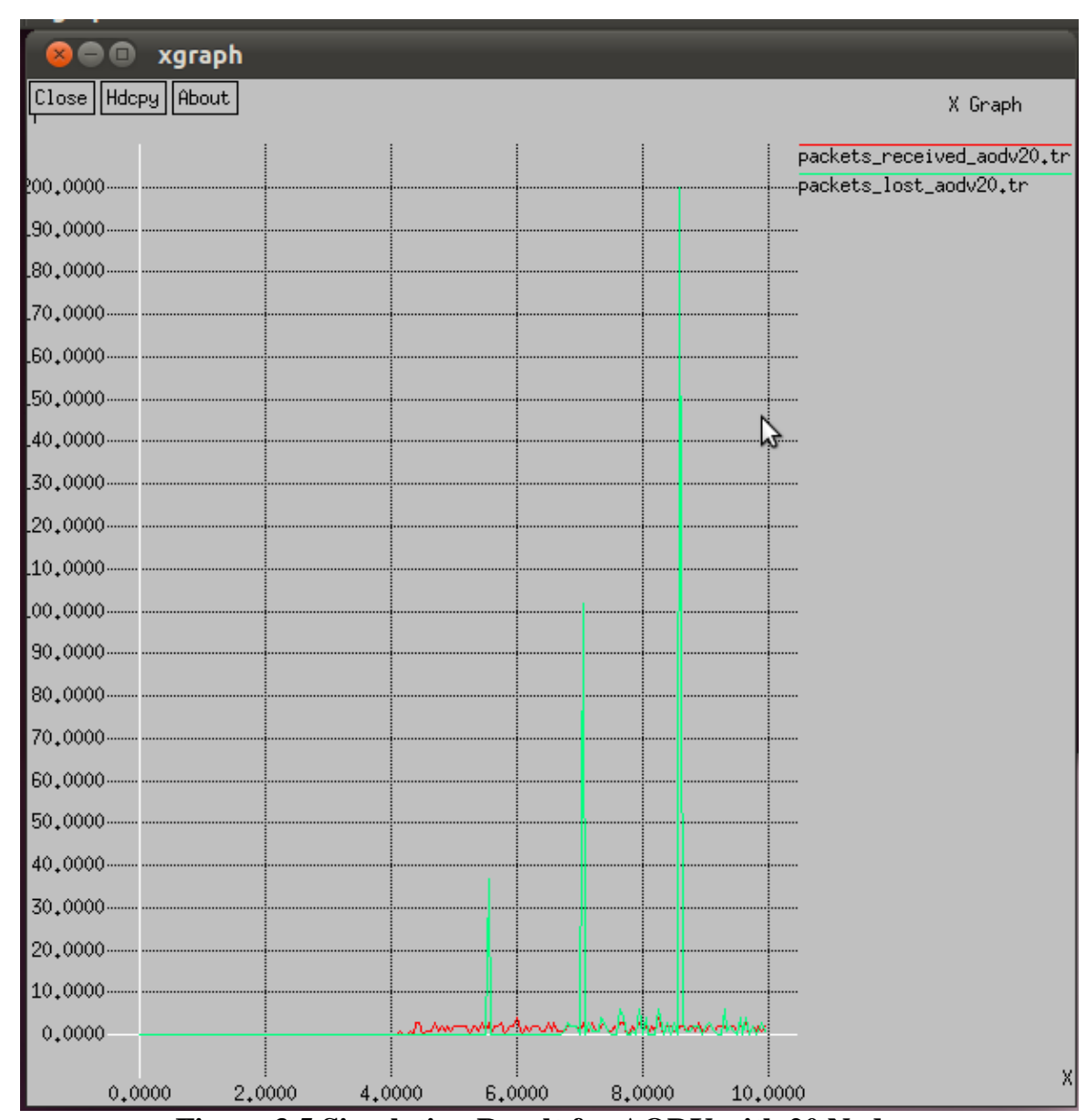

Figure 3.5 Simulation Result for AODV with 20 Nodes 
Performance Comparison of Routing protocols for MANETs.

\begin{tabular}{|l|l|}
\hline Protocols & AODV \\
\hline End-to-End Delay(ms) & 605.967 \\
\hline Throughput(kbps) & 405.06 \\
\hline
\end{tabular}

Table 3.2 Simulation Result for AODV with 20 Nodes

\subsection{Performance Analysis of DSR}

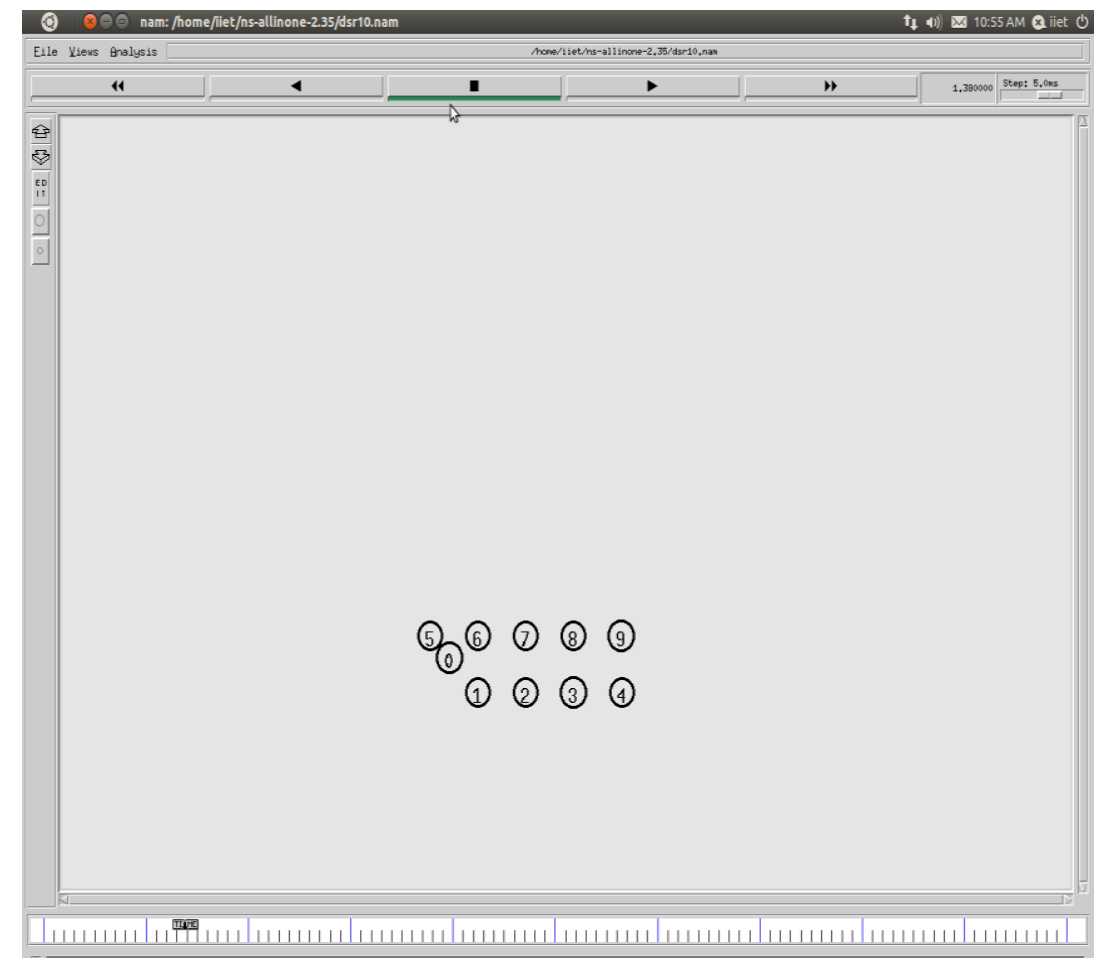

Figure: 3.6 Simulation with DSR Initial stage-I

I quote text box.]

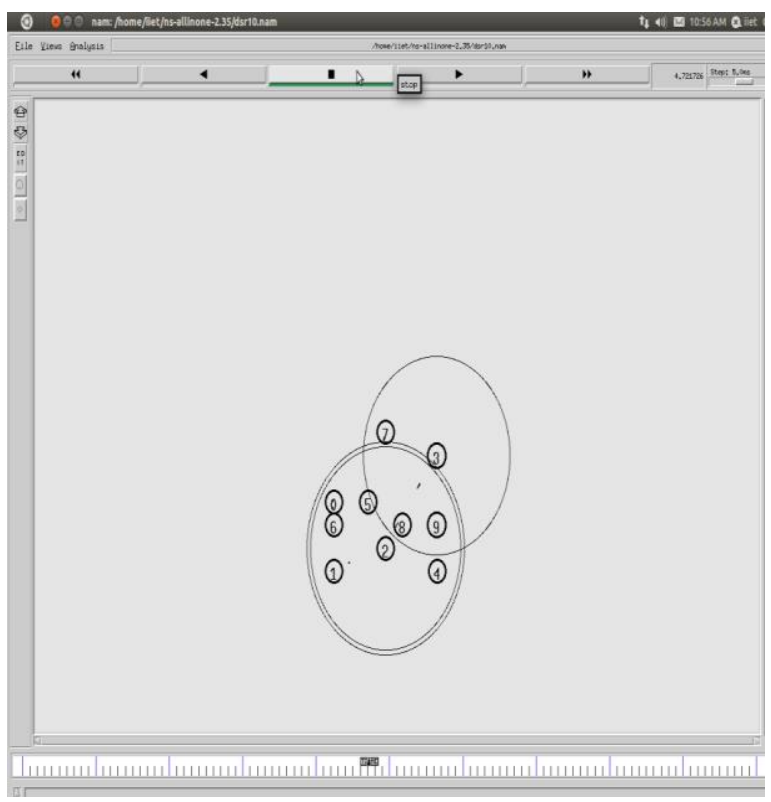

Figure: 3.7 Data transfer DSR

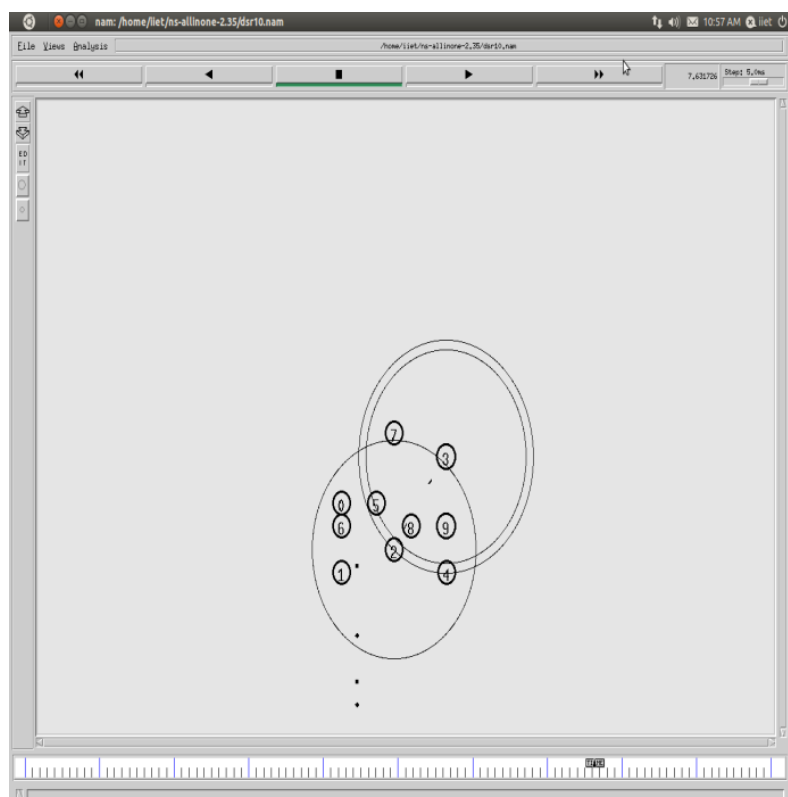

Figure: 3.8 Packet Drop in DSR 


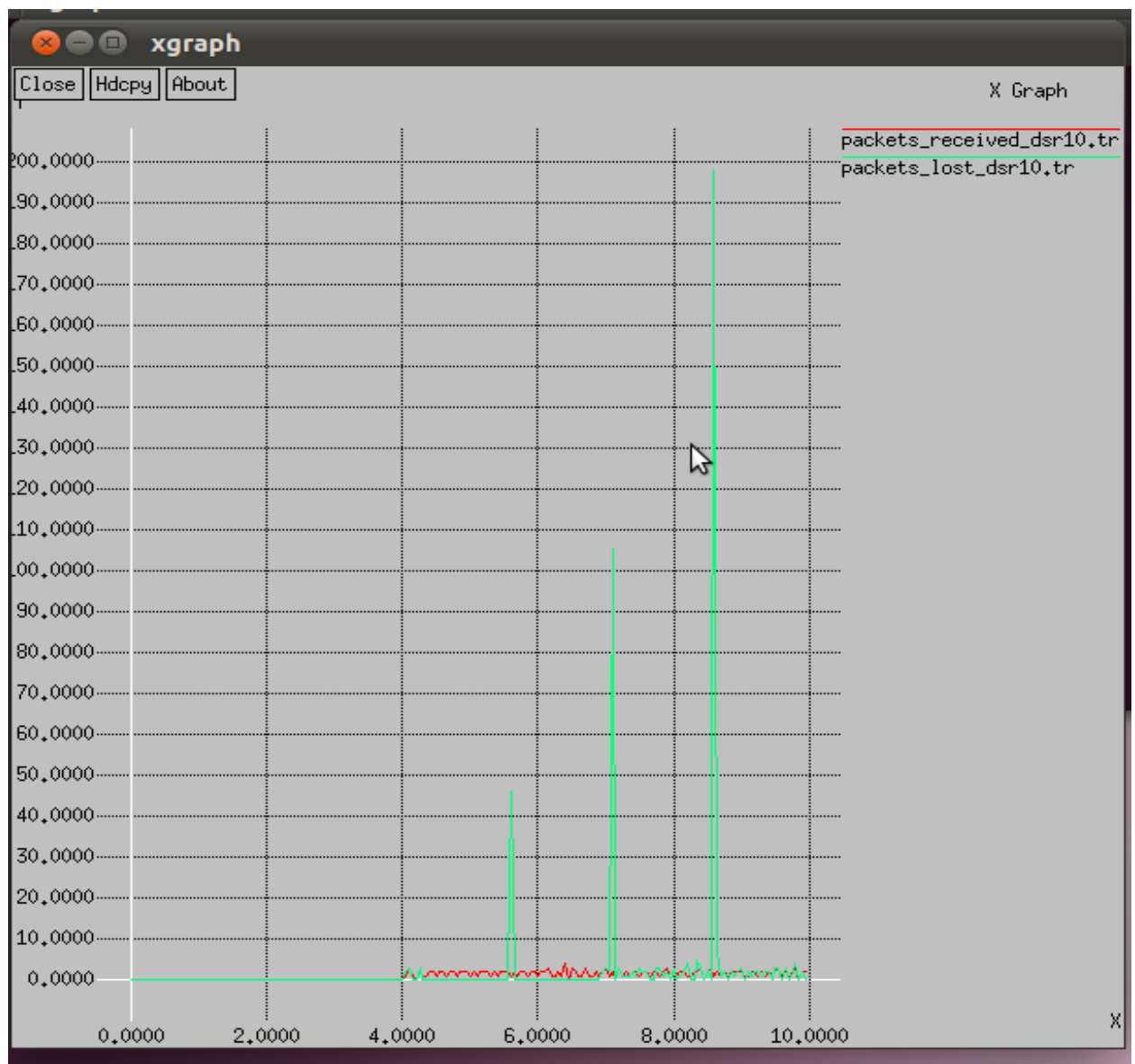

Figure 3.9 Simulation Result for DSR with 10 Nodes

\begin{tabular}{|l|l|}
\hline Protocols & DSR \\
\hline End-to-End Delay(ms) & 365.702 \\
\hline Throughput(kbps) & 409.11 \\
\hline
\end{tabular}

Table 3.3 Simulation Result for DSR with 10 Nodes

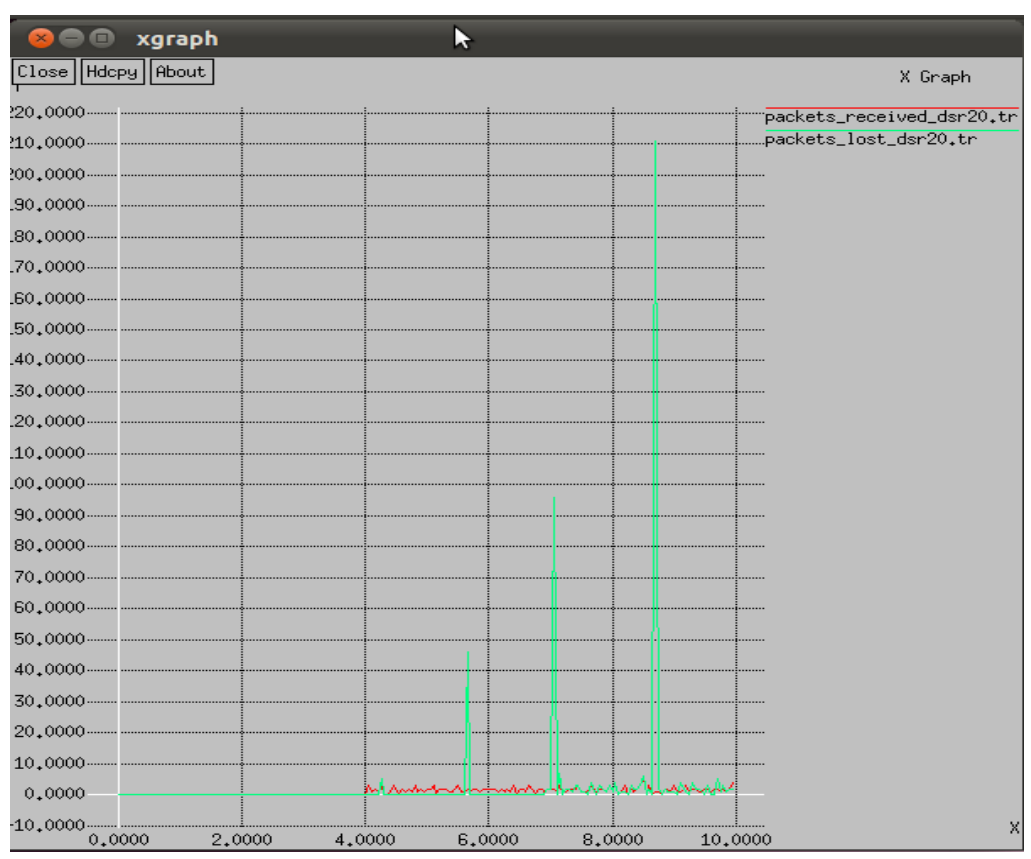

Figure 3.10 Simulation Result for DSR with 20 Nodes 
I quote text box.]

\begin{tabular}{|l|l|}
\hline Protocols & DSR \\
\hline End-to-End Delay(ms) & 367.346 \\
\hline Throughput(kbps) & 407.26 \\
\hline
\end{tabular}

Table 3.4 Simulation Result for DSR with 20 Nodes

III. RESULTS AND DISCUSSION

4.1 Performance Analysis of Routing Protocols

To evaluate the performance of routing protocols, we used different quantitative metrics to compare the performance of the selected protocols. They are as following:

4.1.1 Packet Delivery Ratio: The fraction of packets sent by the application that are received by the receivers. 4.1.2 Throughput: The throughput is defined as the total amount of data a receiver receives from the sender divided by the time it takes for the receiver to get the last packet.

4.1.3 Routing Load: Routing Load is the ratio of total number of the routing packets to the total number of received data packets at destination.

4.1.4 End-to-end delay: End-to-end delay indicates how long it took for a packet to travel from the source to the application layer of the destination.

\subsection{Performance Comparison of protocols}

4.2.1 AODV and DSR (Considering Nodes)

\begin{tabular}{|c|c|c|c|c|}
\hline No. of Nodes & \multicolumn{3}{|c|}{ AODV } & \multicolumn{2}{c|}{ DSR } \\
\hline 10 & $\begin{array}{l}\text { End-to-End } \\
\text { Delay(ms) }\end{array}$ & Throughput(kbps) & $\begin{array}{l}\text { End-to-End } \\
\text { Delay(ms) }\end{array}$ & Throughput(kbps) \\
\hline 20 & 369.072 & 405.39 & 365.702 & 409.11 \\
\hline 30 & $\mathbf{6 0 5 . 9 6 7}$ & 405.06 & 367.346 & 407.26 \\
\hline 40 & 389.324 & $\mathbf{2 7 2 . 6 2}$ & 10.328 & 297.65 \\
\hline $\mathbf{5 0}$ & 398.882 & $\mathbf{4 0 1 . 2 4}$ & 365.346 & 409.23 \\
\hline
\end{tabular}

Table 4.1: Simulation results of AODV and DSR (Considering Nodes)

I quote text box.]

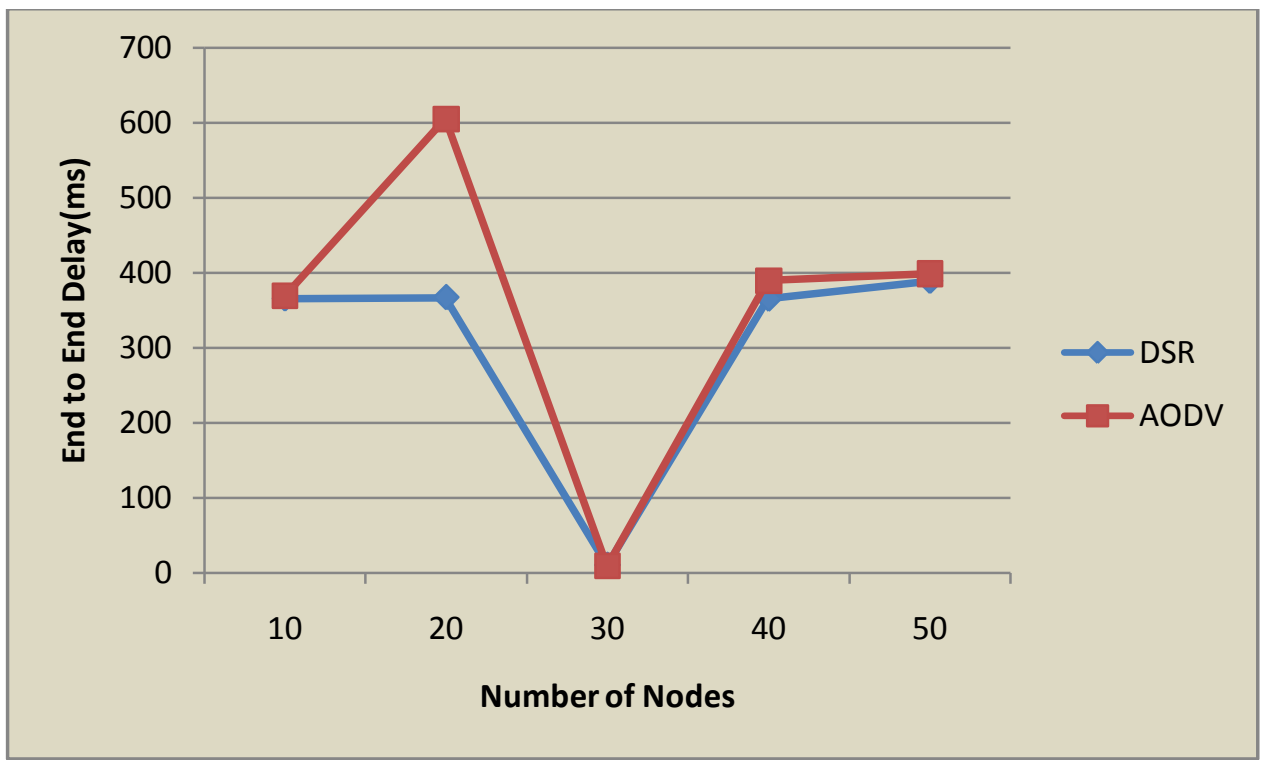

Figure 4.1 Comparison of End-to-End Delay between AODV and DSR (Considering Nodes) 


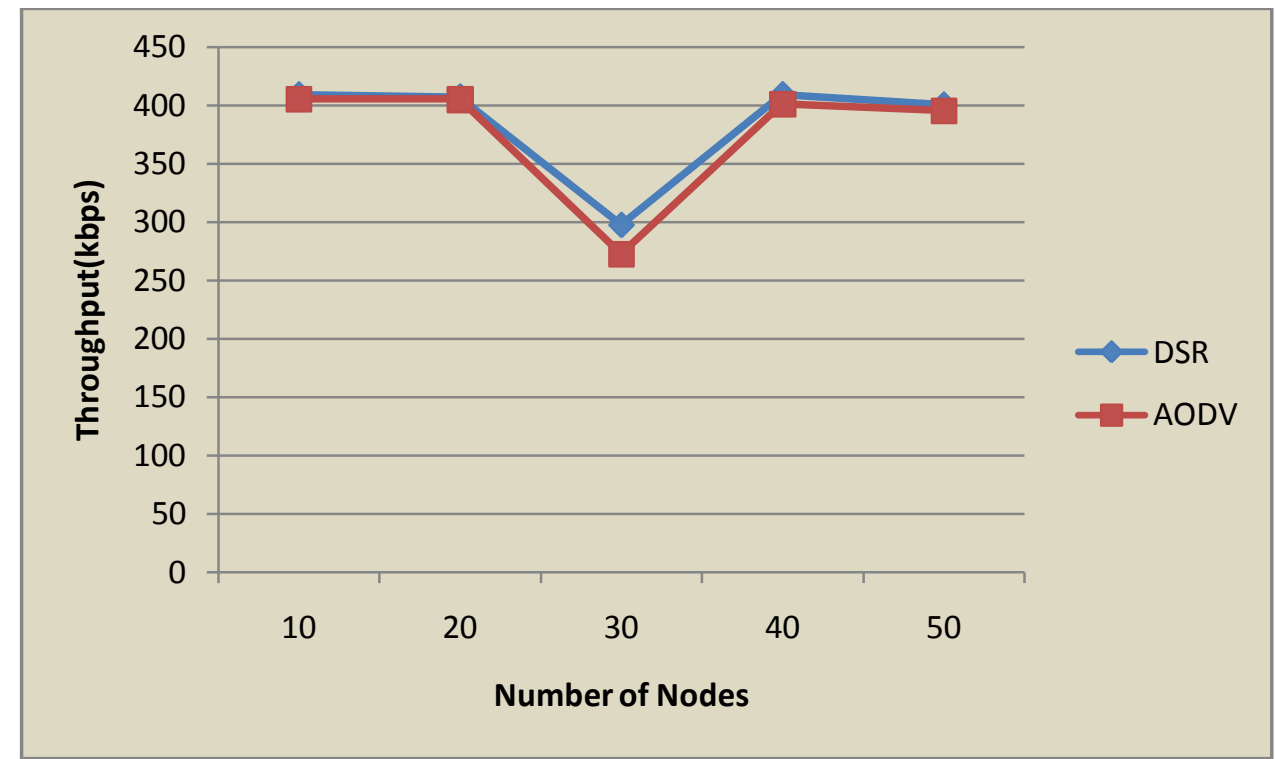

Figure 4.2 Comparison of Throughput between AODV and DSR (Considering Nodes)

4.2.2 AODV and DSR (Considering Pause Time)

\begin{tabular}{|c|c|c|c|c|}
\hline $\begin{array}{l}\text { Pause } \\
\text { Time(ms) }\end{array}$ & \multicolumn{2}{|c|}{ AODV } & \multicolumn{2}{c|}{ DSR } \\
\hline & $\begin{array}{l}\text { End-to-End } \\
\text { Delay(ms) }\end{array}$ & Throughput(kbps) & $\begin{array}{l}\text { End-to-End } \\
\text { Delay(ms) }\end{array}$ & Throughput(kbps) \\
\hline 5 & 369.072 & 405.39 & 365.702 & 409.11 \\
\hline 10 & 369.072 & 405.39 & 365.702 & 409.11 \\
\hline 20 & 369.072 & 405.39 & 365.702 & 409.11 \\
\hline 30 & 369.072 & 405.39 & 365.702 & 409.11 \\
\hline 40 & 369.072 & 405.39 & 365.702 & 409.11 \\
\hline
\end{tabular}

Table: 4.2: Simulation results of AODV and DSR (Considering Pause Time)

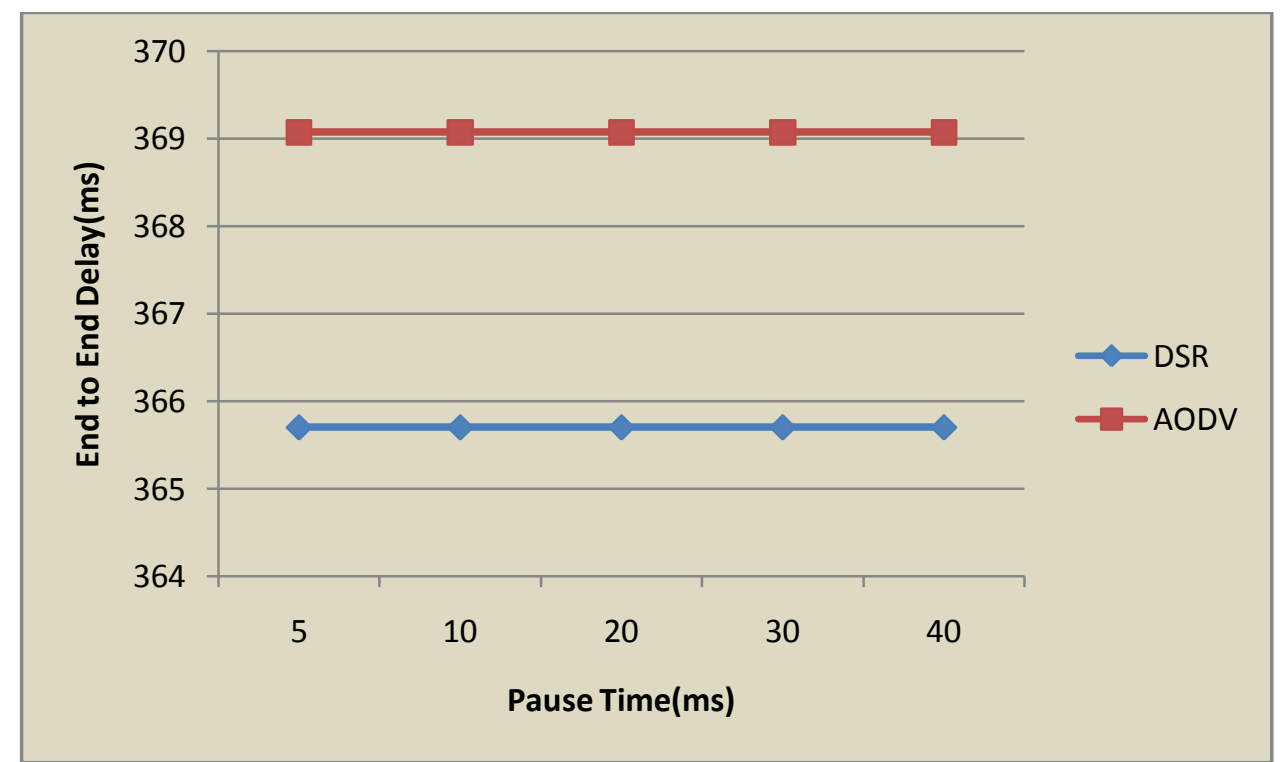

Figure 4.3 Comparison of End-to-End Delay between AODV and DSR (Considering Pause Time) 


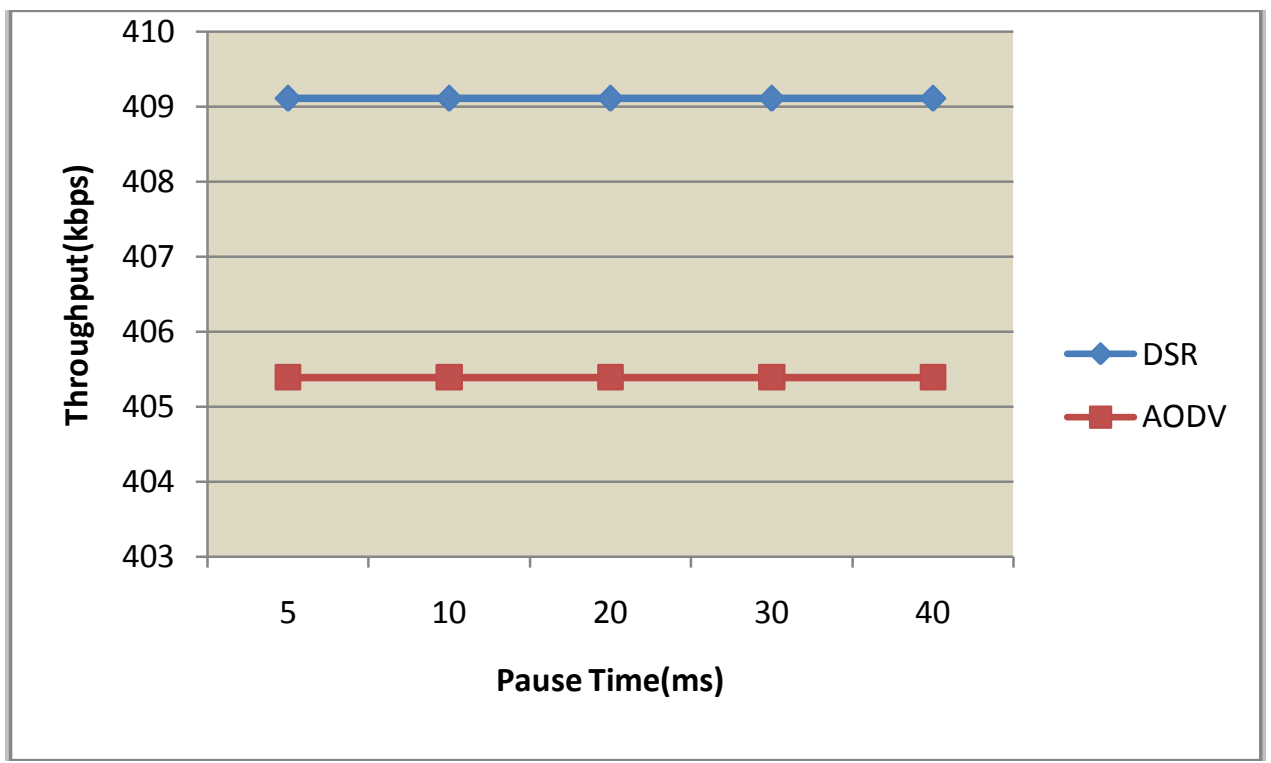

Figure 4.4 Comparison of Throughput between AODV and DSR (Considering Pause Time)

\section{CONCLUSION}

In this dissertation, a mobile ad-hoc network routing protocol DSR and AODV is implemented in ns-2 The performance is analyzed in terms of Throughput, End-to-End delay PDF(Packet Delivery Ratio) and Routing Load.

The experiment was performed considering the number of nodes and pause time. When the number of nodes in a network goes on increasing then the Throughput, End-to-End delay and PDF of the system goes on decreasing. Thus for Throughput and PDF number of nodes in the network should be less but if we take End-toEnd delay into account then the number of nodes should be more.

When the pause time of node (or you can say that mobility) of node keeps on changing then there is no effect on any parameter i.e. on Throughput, End-to-End delay and on PDF. These all parameters are constant because the additional nodes mobility does not proactively exchange routing information.

\section{REFERENCES}

[1] L. Rajaj et.al, "Glo Mo Sim: A Scalable Network Simulation Environment, "Proceedings of MILCOM'99, November 1999.

[2] S.D. Khatawar, Sunil makar ,R K Rathy, "Traffic pattern based performance comparison of AODV, DSDV and OLSR MANET routing protocols using freeway mobility model", International Journal of Computer Science and Information Technologies, Vol. 2 (4), 2012.

[3] Rashmi Rohankar, Ram Murthy and B.S.Manoj, "Ad Hoc Wireless Networks,Architectures and Protocols" Prentice Hall,2012.

[4] Nilesh P.Bobadel ,Behrouz A, Forouzan, "Data Communication and Networking", second edition, Tata McGraw-Hill, 2012.

[5] Thouraya Bouabana, J.Boleng, V. Davies, "A Survey of Mobility Models for Ad Hoc Network Research" on Wireless Communication \& Mobile Computing (WCMC): Special issue on Mobile Ad Hoc Networking: Research, Trends and Applications, pp. 483-502, 2011.

[6] Tai-hoonkim,Laura Marie Feeney, "A Taxonomy for Routing Protocols in Mobile Ad-Hoc Networks", Tech. Report, Swedish Institute of Computer Science, Sweden 2011.

[7] G.Lavanya and David A.Maltz, “Dynamic source Routing in Ad Hoc Wireless networks”. ,chapter 5, pp 153-181, kluwer Academic Publishers,2011.

[8] Asma tuteja,Rajneesh Gujral,Sunil Thalia, "Comparative analysis of DSDV,AODV and DSR Routing protocols in MANET using ns2”, International Conference on Advances in Computer Engineering,2010.

[9] K. Amjad , A.J. Stocker, “ Impact of node density and mobility on the performance of AODV and DSR in MANETs", CSNDSP 2010.

[10] Shaily Mittal, Prabhjot Kaur:" PERFORMANCE COMPARISION OF AODV, DSR and ZRP ROUTING PROTOCOLS IN MANET'S", International Conference on Advances in Computing, Control, and Telecommunication Technologies, 2009. 